\title{
Proposta de seleção e priorização do portfólio de novos produtos em uma empresa têxtil
}

\author{
Mauricio Johnny Loos ${ }^{\mathrm{a} *}$, Paulo Augusto Cauchick Miguel ${ }^{\mathrm{a**}}$ \\ aUniversidade Federal de Santa Catarina, Florianópolis, SC, Brasil \\ *mauricioloos@hotmail.com, **paulo.cauchick@ufsc.br
}

\begin{abstract}
Resumo
A gestão de portfólio de produtos é um dos processos responsáveis por manter a posição competitiva das organizações, alocar adequadamente os recursos de desenvolvimento e assegurar maior objetividade e eficácia na seleção dos projetos de novos produtos. Assim sendo, empresas de diversos setores industriais vêm estruturando seus processos de gestão de portfólio no processo de desenvolvimento de produtos (PDP). Nesse contexto, o presente trabalho objetiva desenvolver uma proposta de seleção e priorização de projetos de novos produtos voltada para uma empresa fabricante de produtos têxteis. Com base em um diagnóstico inicial para identificar oportunidades de melhoria na gestão de portfólio de produtos, é feita uma proposta baseada em critérios tais como: importância estratégica, margem de contribuição, volume de venda previsto, dentre outros. A proposta foi então confrontada com dados históricos advindos de situação real, onde constataram-se alterações significativas na priorização dos produtos a serem desenvolvidos, devido a alguns fatores, dentre os quais os principais foram o superdimensionamento das margens de contribuição e dos volumes de venda. Por meio da comparação na aplicação da proposta, conclui-se que esta possibilita que a seleção e priorização de produtos a serem desenvolvidos pela empresa ocorram de forma mais bem estruturada e criteriosa.
\end{abstract}

Palavras-chave

Gestão de portfólio. Desenvolvimento de produto. Seleção de novos produtos. Empresa têxtil.

\section{Introdução}

Um dos problemas que as organizações de diversos setores industriais enfrentam é associado com a seleção de projetos de novos produtos, como destacam publicações no tema (e.g. Moraes \& Laurindo, 2003; Rabechini Junior et al., 2005; Castro \& Carvalho, 2010). Quando estas organizações buscam suas habilidades para gerar múltiplas ideias para novos produtos que sejam consistentes com a estratégia atual do produto e selecionam os projetos com maior probabilidade de sucesso, o desempenho de novos produtos deve melhorar (McNally et al., 2009).

Muitas vezes observa-se que o portfólio de projetos nas organizações contém projetos que não suportam adequadamente a intenção estratégica; sofrem de sobreposição e duplicação; competem por recursos limitados, não compartilham capacidades de forma adequada, ou excedem a capacidade da organização para a mudança (Lockett et al., 2008). Nesse sentido, Cooper et al. (2000) enfatizam que há duas formas para uma empresa ter sucesso em novos produtos: escolher os projetos certos e executá-los corretamente. 0 gerenciamento de portfólio serve para garantir que o conjunto de projetos escolhido e mantido no portfólio de desenvolvimento deva atender os objetivos organizacionais (Kendall \& Rollins, 2003).

Nesse contexto, o objetivo deste trabalho é desenvolver uma proposta de seleção de projetos de novos produtos em uma empresa do setor têxtil, que vem, cada vez mais, apresentando inovações em produtos, visando combater a concorrência dos países asiáticos. Cabe ressaltar ainda que a literatura internacional, em geral, não aborda o tema de gestão de portfólio no setor têxtil. Além disso não há expressividade em termos de publicações nacionais nesse setor. 0 trabalho pretende focar na seleção e priorização de projeto de produtos, como uma fase inicial para gerir o portfólio de desenvolvimento de novos produtos, visando testar a proposta. A proposta 
é então verificada utilizando-se com dados históricos reais. Esta organização foi escolhida em função de apresentar um cenário propício para a aplicação da proposta de seleção e priorização de novos produtos. 0 trabalho tem características de um trabalho teórico-conceitual, devido à construção de uma proposta com base na teoria vigente, mas também empírica, dada a aplicação realizada. Para cumprir estes objetivos, o trabalho primeiramente estabelece 0 referencial teórico, seguido pelos métodos e técnicas de pesquisa adotados, resultados alcançados e, finalmente, suas conclusões.

\section{Referencial teórico}

A gestão de portfólio é um processo de decisão dinâmico, através do qual uma lista de negócios do novo produto ativo é constantemente atualizada e revisada (Cooper et al., 2001a). De acordo com os autores supracitados, nesse processo, novos projetos são avaliados, selecionados e priorizados; projetos existentes podem ser acelerados, abortados ou não priorizados, e os recursos são alocados e realocados aos projetos ativos. 0 gerenciamento de portfólio avalia uma série de projetos que são desenvolvidos sob a administração de uma unidade organizacional (Archer \& Ghasemzadeh, 1999). Cada projeto pode se relacionar com outros ou ser independente, no entanto, devem fazer parte de objetivos estratégicos determinados e assim buscar recursos na organização. 0 gerenciamento de portfólio serve para garantir que o conjunto de projetos escolhido e mantido no portfólio atenda aos objetivos organizacionais (Kendall \& Rollins, 2003). 0 conceito de portfólio é uma ferramenta de gestão útil para impor uma disciplina na alocação de recursos limitados da empresa para uma melhor combinação das operações da empresa que irá maximizar retornos de longo prazo em determinado nível de risco (Turnbull, 1989).

A gestão de portfólio possui três objetivos (Cooper et al., 1997a): (i) o alinhamento estratégico dos projetos de desenvolvimento com a estratégia do negócio; (ii) a maximização do valor do portfólio levando em consideração os recursos disponíveis; e (iii) o balanceamento entre projetos sob critérios diversos. Para o PMI - Project Management Institute (2008), o objetivo da gestão de portfólio é garantir que a organização esteja fazendo o trabalho certo, ou seja, centrando esforços em projetos que darão retorno e estejam ligados à estratégia do negócio, ao invés de fazer certo um trabalho, o qual pode estar desalinhado com o negócio. 0 gerenciamento de portfólio de projetos tornou-se um fator significativo no sucesso das estratégias de longo prazo das organizações e está relacionado ao papel dos altos executivos e tomadores de decisões-chave que devem validar os investimentos relevantes, além de formular e traçar metas e objetivos (Castro \& Carvalho, 2010).

A abordagem de gerenciamento de portfólio pode fornecer os seguintes benefícios (Mikkola, 2001): a análise sistemática dos projetos; pontos fortes e fracos dos projetos a serem revelados; o consenso entre as diferentes funções; avaliação com respeito aos desempenhos do nível do negócio, e lacunas claras e oportunidades de desenvolvimento futuras, a serem destacadas. 0 gerenciamento de portfólio possibilita uma grande contribuição aos dirigentes das empresas, proporcionando um exame detalhado das dimensões estratégicas que devem nortear o balanceamento do portfólio e permitir a adequada priorização dos projetos, bem como criar mecanismos de controle e descarte de projetos (Rabechini Junior et al., 2005). Cooper et al. (2001a) colocam que o processo de decisão de portfólio engloba um número de processos de decisão dentro da empresa, incluindo avaliações periódicas do portfólio total de todos os projetos, tomando decisões go/no go nos projetos individuais, e desenvolvendo uma estratégia de novos produtos para o negócio, com as decisões de alocação de recursos estratégicos. Com a necessidade de responder rapidamente às dinâmicas necessidades dos clientes, o aumento da complexidade do projeto de produtos e tecnologias em rápida evolução, a seleção do conjunto correto de desenvolvimento de novos produtos é fundamental para o sucesso de uma empresa no longo prazo (Chen et al., 2008). Em decorrência, qualquer proposta para seleção e priorização deve ser uma simplificação da realidade, por isso os requisitos básicos para a seleção dos projetos são os seguintes (Coldrick et al., 2005): avaliação do projeto - exame de projetos individuais para estabelecer se eles são dignos de realizar; seleção de projeto - exame de seleção de uma série de projetos para obter um portfólio atraente.

Escolher entre dezenas ou centenas de alternativas por aquelas que irão compor o portfólio de projetos e a organização de sua prioridade é um assunto complexo de multicritérios de tomada de decisão, cuja solução exige uma definição de critérios claros para a seleção e priorização dos tomadores de decisão (Padovani et al., 2008). Uma das formas de fazer a seleção e priorização de projetos é utilizando modelos de pontuação. Os principais insumos para um modelo de pontuação são (Coldrick et al., 2005): determinação dos critérios; determinação dos pesos; atribuição da pontuação. A principal vantagem de um modelo de pontuação é a sua capacidade para incluir os dados qualitativos e quantitativos. Isto é particularmente aplicável às atividades de Pesquisa e Desenvolvimento (P\&D) no baixo orçamento, onde a avaliação de 
projetos por razões puramente econômicas é de pouco ou nenhum benefício (Coldrick et al., 2005). São seis fatores principais de um sistema genérico de modelo de pontuação desenvolvido para avaliação e classificação de projetos de novos produtos (Cooper et al., 2001b): alinhamento estratégico e importância; produto e vantagem competitiva; atratividade do mercado; aproveitamento das competências essenciais; viabilidade técnica e recompensa financeira. A decisão de investir em um determinado projeto envolve a análise de fatores qualitativos e quantitativos. Existem várias abordagens para seleção de projetos, que podem ser agrupadas nas seguintes categorias (Cooper et al., 2001a): técnicas de medição de benefícios; modelos econômicos; métodos de gestão de portfólio e disponibilidade de pessoas e instalações. Outro importante aspecto a ser considerado na seleção dos projetos é o grau de incerteza gerado pelas características dos projetos e dos recursos alocados em seu desenvolvimento (Moraes \& Laurindo, 2003).

Padovani et al. (2010) colocam que o processo de tomada de decisão é influenciado pelos stakeholders, que fazem parte do processo decisório em cada etapa do ciclo de vida da organização e que tais decisões envolvem trade-offs, que precisam ser conhecidos e avaliados para que a decisão tomada seja a mais adequada. Não importa quão elegantes ou sofisticadas sejam as ferramentas de seleção de portfólio e decisão, se a entrada de informação é pobre, o que pode tornar a tomada de decisão ineficaz (Cooper et al., 2000). McFarlan (1981) afirma que os projetos diferentes exigem abordagens de gestão diferentes. No entanto, o autor citado adverte que as organizações exaustivamente estudam os benefícios financeiros, a qualidade dos projetos, os custos de implementação e competências necessárias, mas elas raramente são preocupadas em manter registros sobre os riscos de projetos. A seleção equivocada de critérios de tomada de decisão pode levar a instituição a não conseguir alcançar seus objetivos estratégicos, bem como os das partes interessadas. Como resultado, o fracasso em introdução de projetos pode se transformar em grandes catástrofes para cada parte envolvida (Padovani et al., 2008).

\subsection{Classificação dos projetos no portfólio e importância do alinhamento da gestão de portfólio com as estratégias organizacionais}

Um dos pontos relevantes para a permanência à frente da concorrência é a classificação de projetos de novos produtos no portfólio. Griffin \& Page (1996) classificam os projetos em baseados em novidade para o mercado e novidade para a empresa (Figura 1), nas seguintes categorias:
1 - Novo para o mundo: os novos produtos que criam um mercado inteiramente novo.

2 - Novo para a empresa: novos produtos que, pela primeira vez, permitem uma empresa entrar em um mercado já estabelecido.

3 - Acréscimo à linha existente: novos produtos que complementam as linhas de produtos estabelecidos de uma empresa.

4 - Melhorias e revisões dos produtos existentes: novos produtos que proporcionam melhor desempenho e maior valor percebido e substituem os produtos existentes.

5 - Reposicionamento: produtos existentes direcionados a novos mercados ou segmentos de mercado.

6 - Redução de custos: novos produtos que proporcionam um desempenho similar a um custo menor.

A classificação de projetos torna-se muito importante no processo de desenvolvimento de produtos, devido ao fato de conseguir transparecer uma melhor compreensão da relação dos projetos com as estratégias da empresa. Outro fator relevante a ser considerado e que se torna facilitado, caso existia uma classificação dos projetos de novos produtos efetuada com qualidade, é o balanceamento de projetos de novos produtos, podendo haver um equilíbrio de projetos condizente com os mercados nos quais as empresas pretendem atuar. No entanto, argumentos contraditórios são identificados. Apesar de alguns autores (e.g. Griffin, 1997; Cooper et al., 2004; Moore, 2010) citarem formas de se implementar a gestão de portfólio, elencando atividades a se executar e não executar, bem como também indicarem formas de os gestores de portfólio se portarem, Castro \& Carvalho (2010) defendem que não existe um processo ou método único de gerenciamento do portfólio de projetos eficaz para todas as organizações. Os responsáveis por implementar o processo de gerenciamento do portfólio de projetos em uma organização devem conhecer as necessidades de sua organização e os modelos de gerenciamento do portfólio de projetos já desenvolvidos e escolher quais etapas e técnicas são

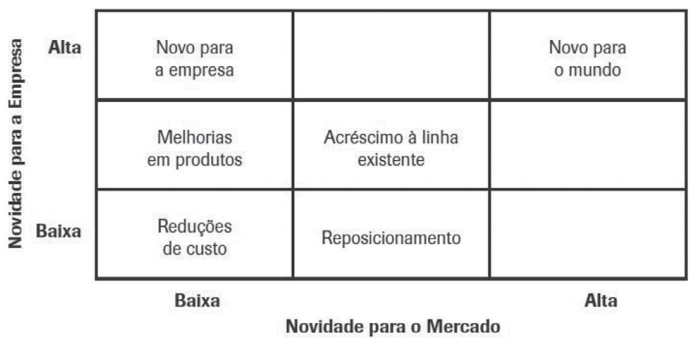

Figura 1. Classificação dos projetos segundo o grau de novidade (Griffin \& Page, 1996). 
mais adequadas (Castro \& Carvalho, 2010). Quanto à remoção e interrupção de projetos no início do processo de desenvolvimento de produtos, Griffin (1997) afirma que as empresas parecem ser mais eficientes na remoção destes projetos, mas Cooper et al. (2000) alegam que parece haver dificuldade em discriminar entre o go/no go dos projetos.

A Tabela 1 apresenta uma série de ideias centrais de diversos autores, enfatizando a importância de se ter o alinhamento da gestão de portfólio com as estratégias organizacionais.

Como pode ser visto na Tabela 1, é importante que critérios estratégicos sejam levados em consideração ao selecionar e priorizar os projetos mais adequados para o desenvolvimento dos produtos. Além disso, a existência de um comitê de portfólio é um importante órgão de tomada de decisão, pois molda o futuro da companhia, por determinação da sua linha de produtos; a linha de produtos bem gerida é essencial para apoiar as vendas e os lucros, fazendo a gestão do portfólio de projetos um fator de sucesso crucial (Lockett et al., 2008)

A partir do referencial teórico sobre a gestão de portfólio, a seção seguinte apresenta os procedimentos metodológicos utilizados para desenvolvimento do presente trabalho.

\section{Métodos e técnicas de pesquisa}

Observa-se na literatura uma escassez de trabalhos, no país, que abordem a gestão de portfólio no setor têxtil, apesar da publicação de Oliveira \& Cheng (2007), a qual objetiva mostrar como a gestão de portfólio pode ser empregada como forma de robustecer o desenvolvimento de produtos em uma empresa do setor têxtil brasileiro. Este fator, juntamente com a existência da necessidade de a empresa estudada reorganizar o seu conjunto de produtos a ser desenvolvido, faz parte da justificativa de escolha do contexto e do objeto de análise. Estes aspectos associados ao acesso facilitado aos dados e informações, devido a um dos autores ter participação nas atividades da empresa, complementam a justificativa de seleção do objeto de análise.

Nesse sentido, o presente trabalho tem características de um trabalho teórico-conceitual, devido ter a construção de uma proposta com base na teoria vigente. A proposta é então verificada com a utilização de dados históricos reais, também apresentando características de um trabalho empírico, similares a um estudo de caso. Esta similaridade ocorre em função do tema ser contemporâneo, bem como pela relevância do contexto de pesquisa (recorte seccional em empresa do segmento têxtil). A escolha do setor justifica-se por ser um dos grandes responsáveis pela movimentação da economia brasileira, com 3,5\% do PIB - Produto Interno Bruto

Tabela 1. Publicações que defendem o alinhamento da gestão de portfólio com as estratégias organizacionais.

\begin{tabular}{|c|c|}
\hline Referências & Ideia central \\
\hline Roussel et al. (1991) & $\begin{array}{l}\text { A gestão de carteiras refere-se a fazer escolhas estratégicas, pelas quais se operacionaliza a } \\
\text { estratégia de seus negócios. }\end{array}$ \\
\hline Cooper et al. (1997a) & $\begin{array}{l}\text { Um dos objetivos da gestão de portfólio é o alinhamento estratégico dos projetos de } \\
\text { desenvolvimento com a estratégia do negócio. }\end{array}$ \\
\hline Cooper et al. (1997b) & $\begin{array}{l}\text { A gestão de carteiras eficaz requer que três elementos estejam no lugar e que trabalhem em } \\
\text { harmonia uns com os outros: a estratégia de negócios, o PDP e a revisão do portfólio com os seus } \\
\text { vários modelos e ferramentas. }\end{array}$ \\
\hline Archer \& Ghasemzadeh (1999) & $\begin{array}{l}0 \text { gerenciamento de portfólio é uma coleção de projetos que são desenvolvidos sob a } \\
\text { administração de uma unidade organizacional. }\end{array}$ \\
\hline Cooper et al. (2001b) & $\begin{array}{l}\text { As metas da empresa, objetivos e estratégias devem ser a base para a seleção do novo portfólio de } \\
\text { produto. }\end{array}$ \\
\hline Kendall \& Rollins (2003) & $\begin{array}{l}0 \text { gerenciamento de portfólio serve para garantir que o conjunto de projetos escolhido e mantido } \\
\text { na carteira deve atender os objetivos organizacionais. }\end{array}$ \\
\hline Moraes \& Laurindo (2003) & $\begin{array}{l}\text { Através do acompanhamento de projeto, deve-se avaliar se os projetos em desenvolvimento } \\
\text { apresentam o alinhamento estratégico desejado, os riscos aceitáveis e o desempenho esperado. }\end{array}$ \\
\hline Rabechini Junior et al. (2005) & $\begin{array}{l}0 \text { gerenciamento de portfólio proporciona um exame detalhado das dimensões estratégicas que } \\
\text { devem nortear o balanceamento da carteira e permitir a adequada priorização dos projetos, bem } \\
\text { como criar mecanismos de controle e descarte de projetos. }\end{array}$ \\
\hline Lockett et al. (2008) & $\begin{array}{l}\text { Em muitas organizações, os projetos são construídos e geridos para atingir as metas funcionais } \\
\text { sem uma visão global de alinhamento estratégico e impacto organizacional. }\end{array}$ \\
\hline Miguel (2008) & $\begin{array}{l}\text { Gestão de portfólio consiste no gerenciamento do conjunto de projetos associados aos objetivos } \\
\text { estratégicos da organização de forma compativel com os recursos disponíveis para sua realização. }\end{array}$ \\
\hline Project Management Institute (2008) & $\begin{array}{l}\text { A meta final da ligação do gerenciamento de portfólio com a estratégia organizacional é } \\
\text { estabelecer um plano equilibrado e executável que irá ajudar a organização a alcançar seus } \\
\text { objetivos. }\end{array}$ \\
\hline Castro \& Carvalho (2010) & $\begin{array}{l}\text { Os projetos devem ser priorizados de acordo com sua importância e contribuição para a estratégia } \\
\text { da organização. }\end{array}$ \\
\hline
\end{tabular}

Fonte: construído pelos autores (2013) com base na análise da literatura. 
(Associação Brasileira da Indústria Têxtil e de Confecção, 2011) e vem, cada vez mais, apresentando inovações em produtos lançados no mercado.

A empresa investigada é de grande porte (com cerca de 3.600 funcionários e aproximadamente $\mathrm{R} \$ 400$ milhões de faturamento anual), possui duas unidades industriais, projetando e fabricando produtos têxteis direcionados para o mercado interno (93\%) e externo (7\%). Os produtos da empresa são divididos em oito famílias principais: (i) "Banho A" (toalhas felpudas de maior valor agregado, ou seja, para as classes A e B), (ii) "Banho B" (toalhas felpudas, mas com um médio valor agregado, para a classe C), (iii) Cama”, (iv) “Mesa”, (v) “Decoração”, (vi) "Praia”, (vii) "Bordar” e (viii) "Roupão”. A empresa conta com um conjunto no seu portfólio de desenvolvimento da ordem de 40 produtos por mês, correspondendo a aproximadamente 400 itens distribuídos entre as oito famílias. Quanto à classificação dos projetos de novos produtos adotada pela empresa, estes são classificados em dois níveis de inovação: "incremental" (melhorias feitas nos produtos e processos que não exigem grande esforço e que não demandam muito tempo de implementação) e "radical" (desenvolvimento de produtos ou processos novos para as empresas ou consumidores), sendo que aqueles não classificados em um destes dois níveis são categorizados como "não inovadores". 0 faturamento médio ocorrido ficou entre 5\% e 6\% para os produtos incrementais e menos de $1 \%$ para os produtos radicais (período de 2008-2010), ficando o restante do faturamento com os produtos não inovadores.

0 desenvolvimento do trabalho se deu por meio das cinco etapas (sendo que algumas se desdobram em etapas subsequentes), conforme apresentadas na Figura 2:
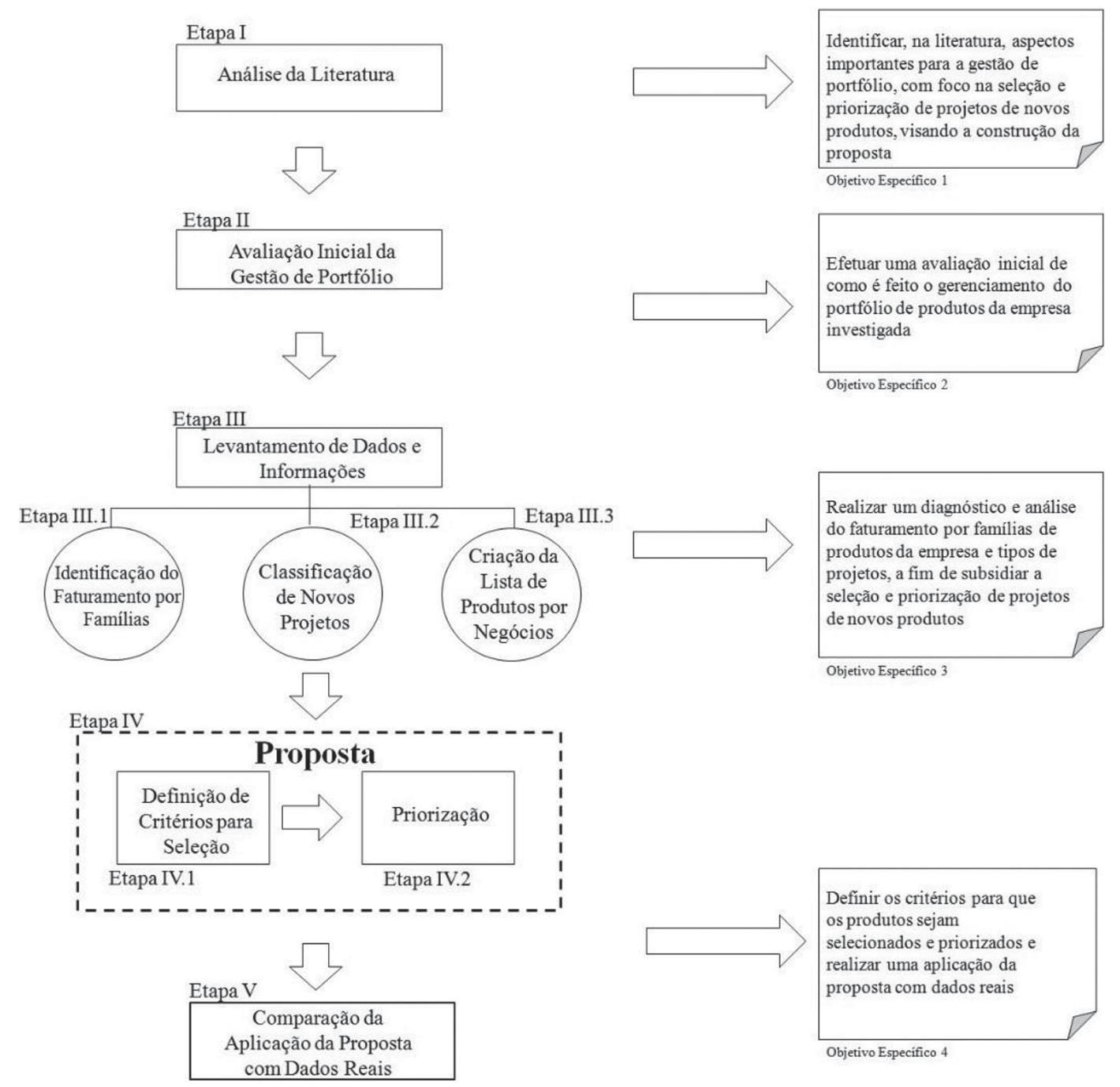

Figura 2. Etapas de desenvolvimento do trabalho. Fonte: Elaborado pelos autores (2013). 
Etapa 1 - Análise da literatura: consiste na construção de uma fundamentação teórica referente à gestão de portfólio, apresentada no tópico anterior.

Etapa 11 - Avaliação inicial: refere-se a um diagnóstico inicial de como a empresa (objeto de análise) conduz a sua gestão de portfólio, por meio da aplicação de um questionário respondido pelo gerente de Engenharia de Produtos e Processos (EPP) e pela coordenadora da área de Produto. Este questionário é baseado em uma survey sobre o gerenciamento de portfólio da PDMA - Product Development and Management Association (2010). A descrição e resultados mais detalhados dessa etapa podem ser vistos em Loos \& Miguel (2012).

Etapa 111 - Levantamento de dados e análise: são análises estatísticas (descritivas) e conceituais, dividindo-se em três outras etapas:

Etapa 111.1 - Faturamento por família: é a análise da distribuição do faturamento da empresa por famílias de produtos, buscando-se entender os motivos desta distribuição, relacionando-os com o PDP (a descrição e resultados mais detalhados dessa etapa podem ser vistos em Loos \& Miguel, 2011).

Etapa 111.2 - Classificação de novos projetos: consiste na análise de como a empresa classifica seus novos projetos e em uma posterior reclassificação dos seus projetos a partir da proposta de Griffin \& Page (1996), levando em consideração o grau de novidade para o mercado e para a empresa. De modo análogo à etapa anterior, a descrição e resultados mais detalhados dessa etapa podem ser vistos em Loos \& Miguel (2011).

Etapa 111.3 - Obtenção de lista de produtos por negócios: compreende a definição de quais famílias terão seus produtos utilizados para a seleção e priorização (Loos \& Miguel, 2011), a qual ocorrerá por meio das definições descritas nas etapas seguintes. Também apresenta uma análise mais detalhada destes produtos, auxiliando nas interpretações necessárias nas próximas etapas.

Uma síntese das etapas ll e 111 é mostrada no Anexo 1.

Etapa IV - Proposta de gestão de portfólio: refere-se ao desenvolvimento focado na seleção e priorização de novos produtos na empresa selecionada. Esta etapa divide-se nas seguintes:

Etapa IV.1 - Definição de critérios para seleção: consiste na escolha de quais critérios são relevantes para a seleção dos novos produtos, sendo estes critérios ligados à literatura bem como às estratégias organizacionais.
Etapa IV.2 - Priorização: refere-se à priorização de produtos reais da empresa, definindo a sequência com que os mesmos deveriam ser desenvolvidos, visando que os produtos mais adequados, sob o ponto de vista de priorização no portfólio, sejam desenvolvidos.

Etapa V - Comparação da aplicação da proposta com dados históricos reais: consiste em avaliar dados históricos reais de produtos que foram desenvolvidos e compará-los com a priorização efetuada pela proposta, visando avaliar os resultados da priorização.

0 presente trabalho compreende as etapas de construção da proposta para a seleção e priorização dos projetos de novos produtos (etapa IV) e sua aplicação (etapa V). As etapas 11 e 111 são, respectivamente, apresentadas em Loos \& Miguel (2011, 2012), e uma sintese dos resultados encontra-se no Anexo 1. Para a construção da proposta (etapa IV), foram conduzidos os seguintes passos, conforme ilustrado na Figura 3.

1 - Definir quais critérios para seleção e priorização devem ser levados em consideração: este passo é essencial para que a seleção e priorização de projetos de novos produtos ocorram de modo eficaz, sendo que deve-se entender quais critérios são considerados importantes para as famílias de produtos que pretendem-se selecionar e priorizar. No presente trabalho, os critérios definidos como importantes para serem utilizados na proposta provenientes da base teórica efetuada da literatura foram: impacto na estratégia empresarial; estágio de "ativo" ou "em espera"; dificuldade tecnológica; objetivo; margem de contribuição e expectativa de vigência, conforme mostra a Tabela 2. Outros critérios identificados também como necessários para a proposta foram obtidos por meio de levantamento no comitê de executivos, estabelecido para essa definição foram os seguintes: origem dos projetos; classe de "plataforma" ou "derivativo"; volume de vendas e importância entre "comum" ou "especialidade".

2 - Lançar os produtos na planilha de priorização: neste passo os produtos são lançados em uma planilha criada a partir dos critérios de seleção e priorização, no intuito de se ter uma organização e ordenação que facilite a priorização dos produtos. Cada um dos campos da planilha encontra-se mais bem detalhado mais à frente.

3 - Priorizar os produtos de acordo com os critérios definidos: com os critérios definidos e com os produtos lançados na planilha, efetua-se neste passo a priorização dos mesmos. A priorização é efetuada 


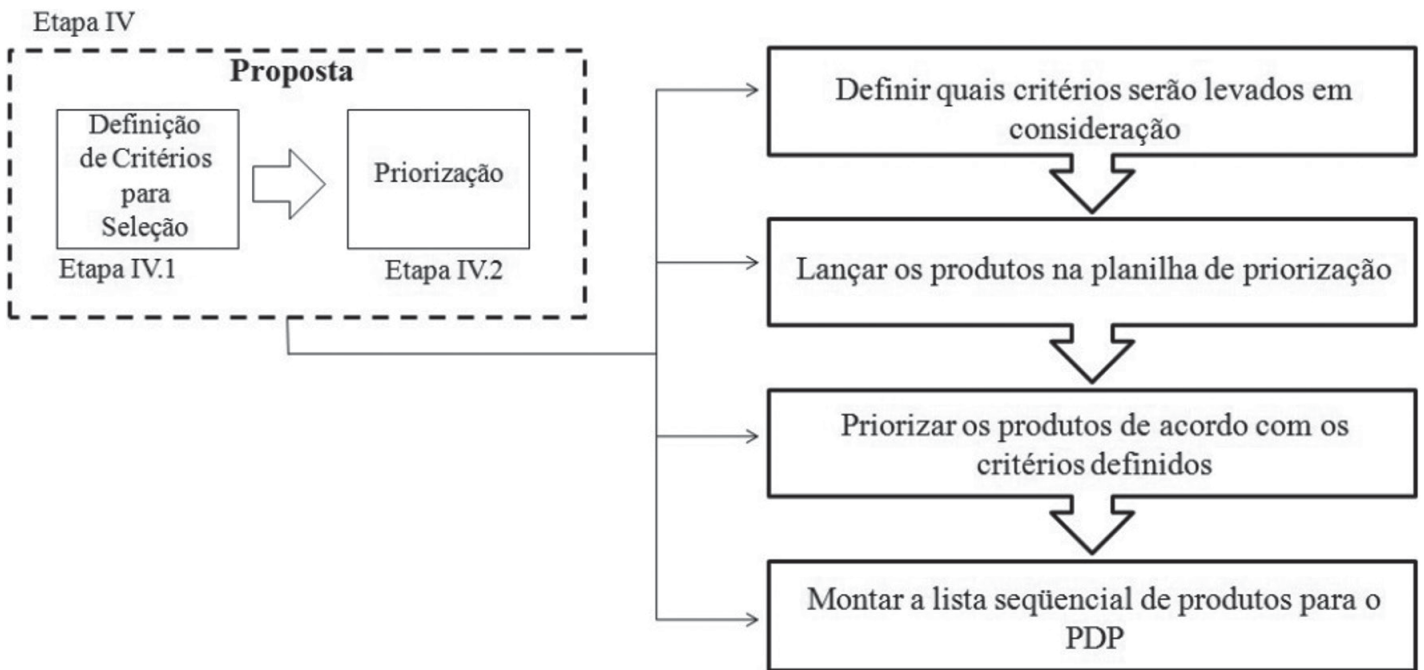

Figura 3. Construção da proposta do trabalho. Fonte: Elaborado pelos autores (2013).

Tabela 2. Critérios de seleção e priorização de projetos e autores.

\begin{tabular}{|c|c|}
\hline Critérios & Referências \\
\hline Estágio (ativo, espera) & Cooper et al. (2000, 2001a); Miguel (2008). \\
\hline Impacto estratégico/Alinhamento estratégico & $\begin{array}{l}\text { Roussel et al. (1991); Cooper et al. (1997a, b, 1998, 2001b); Archer \& Ghasemzadeh } \\
\text { (1999); Kendall \& Rollins (2003); Moraes \& Laurindo (2003); Rabechini Junior et al. } \\
\text { (2005); Lockett et al. (2008); Miguel (2008); Project Management Institute (2008); } \\
\text { Castro \& Carvalho (2010). }\end{array}$ \\
\hline Objetivo do projeto & Griffin \& Page (1996). \\
\hline Rentabilidade (margens, recompensa financeira) & $\begin{array}{l}\text { Cooper et al. (1998); Cooper et al. (2001b); Hamilton (2002); Project Management } \\
\text { Institute (2008). }\end{array}$ \\
\hline $\begin{array}{l}\text { Tecnologia (dificuldade tecnológica, } \\
\text { desenvolvimento tecnológico) }\end{array}$ & $\begin{array}{l}\text { Roussel et al. (1991); Gunasekaran (1998); Poolton \& Barclay (1998); Cooper et al. } \\
\text { (2000, 2001b); Rozenfeld et al. (2006); Chen et al. (2008). }\end{array}$ \\
\hline $\begin{array}{l}\text { Tempo (ciclo de vida e vigência; tempo para o } \\
\text { mercado, redução de tempo) }\end{array}$ & $\begin{array}{l}\text { Wit (1988); Mahdi \& Alreshaid (2005); Cooper et al. (1998); Project Management } \\
\text { Institute (2008). }\end{array}$ \\
\hline
\end{tabular}

Fonte: Construído pelos autores (2013) com base na análise da literatura.

pelo tomador de decisão de forma individual, ou seja, cada produto requer uma análise, usando os critérios estabelecidos para essa avaliação.

4 - Montar a lista sequencial de produtos para o processo de desenvolvimento de produto (PDP): neste passo, após a seleção e priorização efetuada, faz-se uma relação dos produtos a serem desenvolvidos posteriormente no PDP, no intuito de indicar a sequência para que o desenvolvimento ocorra.

Em linhas gerais, para a coleta de dados, diversas fontes de evidência foram utilizadas, sendo estas: reuniões de portfólio, reuniões de cronogramas, análise documental, questionário PDMA, entrevistas semiestruturadas e entrevistas não estruturadas.

Em relação à seleção e priorização de produtos, observa-se que o método AHP (Analytic Hierarchy Process) e a programação inteira são bastante utilizados, formando um modelo de decisão híbrido. Este modelo de decisão não foi utilizado no presente trabalho, mas sim o modelo de pontuação. Padovani et al. (2010) sugerem que o método AHP não é o mais indicado para selecionar projetos quando o número de opções é superior a 100, pois as comparações aos pares despendem um tempo muito longo, e pelo fato de o autor do presente trabalho decidir considerar a necessidade de se ter uma proposta de seleção e priorização de produtos mais simplificada, para possibilitar testar a mesma.

A partir da descrição dos métodos e técnicas, na sequência são apresentados os resultados do trabalho, visando atender os seus objetivos.

\section{Resultados}

Este tópico apresenta os resultados relativos às etapas IV e V, de acordo com os propósitos inicialmente estabelecidos. 


\subsection{Critérios para seleção e priorização}

Para que se tenha a representação do portfólio de produtos, uma planilha de seleção e priorização de novos produtos foi criada. Essa planilha é composta pela série de critérios considerados como importantes para a tomada de decisão, para auxiliar na seleção dos projetos para serem desenvolvidos. Conforme enfatizado por Cheng (2000), há a necessidade do balanceamento entre projetos porque, por exemplo, não seria possível para a sobrevivência de uma empresa desenvolver somente projetos de alto risco ou projetos de longa duração - é necessário obter equilíbrio entre os extremos de cada um dos critérios, e, por este motivo, os critérios para priorização de produtos foram diferenciados para as famílias de produtos "Banho A" e "Banho B", conforme mostrado mais adiante. A Figura 4 mostra o cabeçalho da planilha criada (para efeito de representação gráfica, na figura o cabeçalho é dividido em duas partes).

Os campos da planilha de seleção e priorização de produtos (Figura 4) compreendem:

\section{- Número do produto}

Identificação numérica do produto. Neste trabalho, os produtos das famílias de produtos "Banho A" e "Banho B";

- Negócios

Negócio/família onde o produto está inserido ("Banho A" ou "Banho B").

- Impacto na estratégia empresarial

Classificação como "alto", "médio" ou "baixo", sinalizando em quais aspectos: participação de mercado, agregação de valor, expansão de novos mercados, fazer frente à concorrência, bem como outros que a empresa possa considerar no momento da avaliação.

\section{- Estágio}

Produto "ativo" (em desenvolvimento) ou "em espera" (a ser desenvolvido). Para o presente trabalho, como os produtos que foram considerados já haviam sido desenvolvidos, todos foram considerados como ativos.
- Origem

Informação se a ideia do produto originou-se na própria empresa ou de demanda de clientes.

- Dificuldade tecnológica (para o desenvolvimento do produto):

"Alta", "média" ou "baixa".

\section{- Classe}

Indicação se o projeto é do tipo "plataforma" ou "derivativo", sendo que os projetos "plataforma" representam um novo "sistema" de solução para os clientes, envolvem mudanças significativas tanto para o processo de fabricação quanto para o projeto do produto, ou para ambos (Miguel, 2008). Já os projetos “derivativos" são também denominados de projetos de sustentação, que podem variar desde versões de custo reduzido de um produto existente até projetos de melhoria de um processo de produção existente (Miguel, 2008).

\section{- Objetivo}

Classificação do produto na estrutura de Griffin \& Page (1996), a qual leva em consideração o nível de inovação para o mercado e para a empresa, classificado como (Griffin \& Page, 1996): "novo para o mundo" (os novos produtos que criam um mercado inteiramente novo), "novo para a empresa" (novos produtos que, pela primeira vez, permitem uma empresa entrar em um mercado estabelecido), "acréscimo à linha existente" (novos produtos que complementam as linhas de produtos estabelecidos de uma empresa), "melhorias e revisões dos produtos existentes" (novos produtos que proporcionam melhor desempenho e maior valor percebido e substituem os produtos existentes), "reposicionamento" (os produtos existentes, direcionados a novos mercados ou segmentos de mercado) e "redução de custos" (novos produtos que proporcionam desempenho semelhante a um custo menor).

A Figura 5 ilustra a classificação dos projetos da empresa conforme Griffin \& Page (1996). Nota-se que grande parte do faturamento da empresa nos três anos analisados (2008-2010) se deu em produtos que compõem a classificação "acréscimo à linha existente",

\begin{tabular}{|c|c|c|c|c|c|c|c|c|c|c|c|c|c|c|}
\hline Produto & & & mpacto n & na Estra & tégia Empresarial & & tágio & Oris & gem & Dificul & lade Tes & nológica & $\mathrm{Cla}$ & isse \\
\hline $\mathrm{N}^{\circ}$ & Negócios & Alto & Médio & Baixo & Em quais aspectos? & Ativo & Espera & Empresa & Clientes & Alta & Média & Baixa & Plataforma & Derivativo \\
\hline
\end{tabular}

\begin{tabular}{|c|c|c|c|c|c|c|c|c|c|c|c|c|c|}
\hline \multicolumn{6}{|c|}{ Objetivo (Griffin e Page) } & \multicolumn{2}{|c|}{ Previsão de Vendas } & \multicolumn{3}{|c|}{ Expectativa de vigência } & \multicolumn{2}{|c|}{ Importância } & Prioridade \\
\hline $\begin{array}{c}\text { Novo } \\
\text { para a } \\
\text { empresa }\end{array}$ & \begin{tabular}{|l|} 
Novo \\
para o \\
mundo
\end{tabular} & $\begin{array}{c}\text { Acréscimo à } \\
\text { linha } \\
\text { existente }\end{array}$ & \begin{tabular}{|c|} 
Melhoria \\
em \\
produtos
\end{tabular} & $\begin{array}{c}\text { Redução de } \\
\text { Custo }\end{array}$ & $\begin{array}{c}\text { Reposicio- } \\
\text { namento }\end{array}$ & $\begin{array}{c}\text { Volume } \\
\text { médio/Mês }\end{array}$ & $\begin{array}{c}\text { Margem } \\
\text { Objetivo } \\
\%\end{array}$ & $\begin{array}{c}6-12 \\
\text { meses }\end{array}$ & $\begin{array}{l}1-2 \\
\text { anos }\end{array}$ & $\begin{array}{l}>2 \\
\text { anos }\end{array}$ & Especialidade & Comum & \begin{tabular}{l|l|l|l|l|l}
1 & 2 & 3 & 4 & 5
\end{tabular} \\
\hline
\end{tabular}

Figura 4. Cabeçalho da planilha de seleção e priorização de produtos. Fonte: Elaborado pelos autores (2013) com base na análise dos dados de campo. 


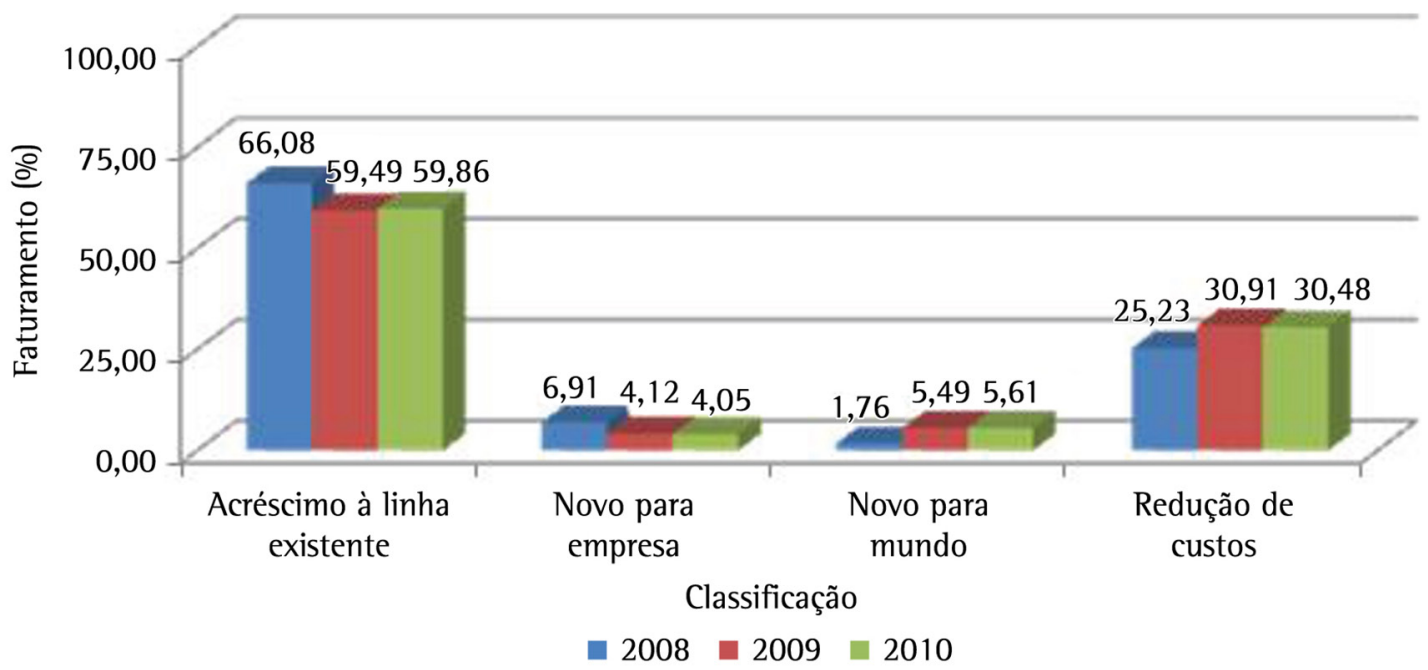

Figura 5. Percentual de faturamento de acordo com a classificação de projetos de novos produtos (Loos \& Miguel, 2011).

ficando em média em 61\% para os três anos analisados. A segunda classificação na qual se obteve grande faturamento foi em "redução de custos", tendo em média 29\%. As classificações "novo para a empresa" e "novo para o mundo" ficaram em média com 5\% de faturamento cada.

A classificação de Griffin \& Page (1996) adotada permite uma interpretação adequada de como os produtos estão posicionados em relação aos níveis de inovação, bem como também das estratégias atreladas a cada tipo de classificação, conforme justificado em cada tipo de classificação anteriormente mostrada, o que faz com que se tenha uma melhor visão de para onde os esforços estão sendo direcionados. Isto se ratifica ainda mais com as colocações de Meyer (1997) e de Wei \& Chang (2011), que afirmam que a empresa precisa definir sua estratégia de desenvolvimento de novos produtos a partir da estratégia de negócio da organização, tendo a necessidade de definir qual o nicho de mercado que a plataforma pretende atingir.

- Previsão de vendas: volume médio de vendas mensal/anual previsto para cada produto, bem como o percentual de margem de contribuição previsto.

- Expectativa de vigência (do produto no mercado): classificado nas faixas de 6-12 meses, 1-2 anos, e maior que 2 anos.

- Importância do produto: classificado em "comum" ou uma "especialidade".

- Prioridade: escala de prioridade, entre 1 e 5 (sendo 1 o mais prioritário), visando definir a sequência no processo de desenvolvimento de produtos. A escala de prioridade de 1 a 5 foi definida devido ao fato de que a quantidade de desenvolvimentos efetuados pela empresa é significativa.

Cada produto, dentro de sua família, é avaliado de forma individual, com base nos critérios, pois, para cada situação, depende um julgamento. Por exemplo, pode-se ter um produto com uma margem de contribuição pretendida maior e volume menor do que outros produtos e vice-versa, gerando a necessidade de estabelecer um trade-off. Não necessariamente para cada atribuição de priorização existirá apenas um produto, pois vários produtos podem se enquadrar dentro de uma mesma configuração de critérios.

Considera-se que é de grande importância que a priorização das duas famílias ocorra de forma separada. Caso não fosse desta forma, poderia se cometer o erro de priorizar apenas produtos de uma das duas famílias, deixando outra de lado. 1sto também remeteria a não consideração da constatação feita no diagnóstico feito pelo instrumento da survey do PDMA (Loos \& Miguel, 2012), quanto aos fatores de priorização de produtos, sendo para a empresa pesquisada: "extremamente importante": alinhamento estratégico, posição competitiva, receita, margens e pontuação de risco; "muito importante": posição da marca, a disponibilidade de recursos; e "importante": fatia de mercado. Todos os fatores citados anteriormente possuem, de certo modo, ligação com a separação das duas famílias de produtos para a priorização.

\subsection{Seleção e priorização dos projetos}

Todos os produtos das famílias "Banho A" e "Banho B" foram classificados na planilha de seleção 
e priorização de produtos (Figura 4), no intuito de se ter uma visão final de como seriam selecionados e priorizados. A escolha dessas famílias deve-se por representarem mais de $60 \%$ do faturamento da empresa (Loos \& Miguel, 2011). 0 total foi de 201 produtos de coleção, ou seja, são produzidos por iniciativa da empresa, e não por solicitação dos clientes, sendo 152 da família "Banho A" e 49 da família "Banho B". A classificação foi efetuada pela área de Engenharia de Produto e Processo, com o auxílio de um dos autores, isto é, para cada produto, preencheu-se a planilha de seleção e priorização (Figura 4) e efetuou-se a avaliação de como cada produto foi classificado entre os diversos critérios, atribuindo-se então uma prioridade.

Antes de apresentar o resultado da priorização efetuada, algumas informações, extraídas do preenchimento da planilha de seleção e priorização de produtos, são apresentadas a seguir, visando enriquecer o entendimento sobre o comportamento dos 201 produtos que fizeram parte da análise. Essas informações envolvem: (i) impacto estratégico; (ii) dificuldade tecnológica; (iii) tipo de classe; (iv) tipo de objetivo; (vi) vigência em mercado; e (vii) importância.

Em relação à quantidade de produtos por tipo de impacto estratégico, nota-se por meio da Figura 6 que a família de produtos "Banho $A$ " teve 14 produtos (9,21\% do total) com alto impacto estratégico, 12 produtos $(7,89 \%$ do total) com médio impacto estratégico e 126 produtos ( $82,90 \%$ do total) com baixo impacto estratégico. A família de produtos "Banho B"

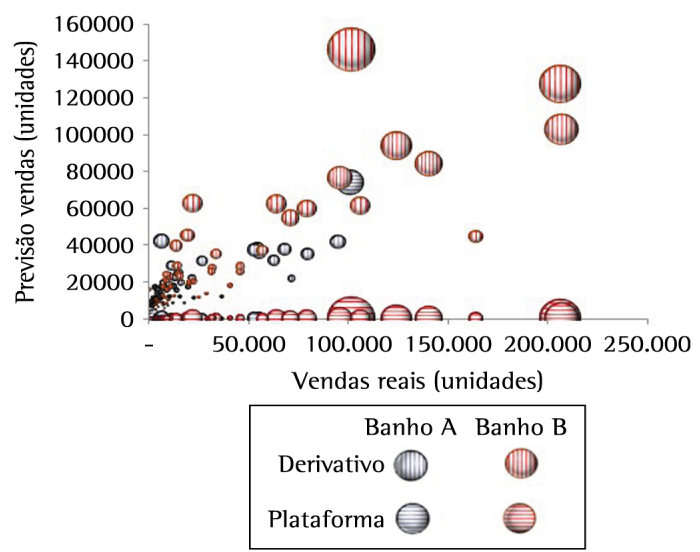

Figura 6. Quantidade de produtos por tipo de impacto estratégico (2008-2010). Nota: 0 tamanho da bolha indica a proporção da previsão de vendas em relação ao total das famílias (unidades); A previsão de vendas significa o volume esperado de vendas para os produtos no período 2008-2010, enquanto que as vendas reais significam o volume, em unidades, vendido dos produtos no mesmo período (2008-2010). Fonte: Construído pelos autores (2013) com base na análise dos dados de campo. apresentou todos os seus produtos como sendo de baixo impacto estratégico. Esta estratificação ocorreu devido à diferença de valor agregado aos produtos nas diferentes famílias. Os produtos da família "Banho A" têm maior agregação de valor do que os produtos da família "Banho B", devido os produtos serem mais bem elaborados, com características diferentes, visando um mercado-alvo diferenciado.

Quanto à dificuldade tecnológica, a Figura 7 mostra que 9 produtos (5,92\% do total) da família de produtos "Banho A" classificaram-se com "alta dificuldade", 6 (3,95\% do total) com "média" e 137 produtos (90,13\% do total) com "baixa dificuldade" tecnológica. Já em relação aos produtos da família "Banho B", todos os 49 são considerados de "baixa dificuldade" tecnológica. Isto ocorre devido ao fato de que os produtos desta família de produtos são mais simplificados, não exigindo utilização tecnológica mais avançada, seja no desenho ou na sua fabricação.

Quanto à quantidade de produtos por tipo de classe, a Figura 8 mostra que 15 produtos (9,87\% do total) da família de produtos "Banho A" classificaram-se como "plataforma”, devido alguns envolverem mudanças significativas no processo de fabricação e outros no desenho do produto; 137 (90,13\% do total) produtos classificaram-se como "derivativo". Dos produtos da família "Banho B", todos os 49 são classificados como "derivativo", devido alguns terem o custo reduzido a partir de um produto existente, e serem projetos de melhoria de um processo de produção existente. Alguns apresentam pouca ou nenhuma alteração de
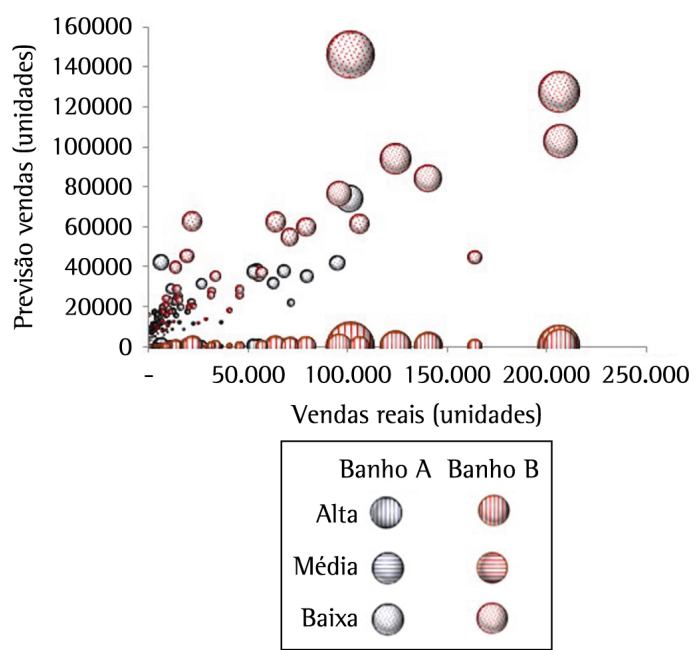

Figura 7. Quantidade de produtos por tipo de dificuldade tecnológica (2008-2010). Nota: Tamanho da bolha - proporção da previsão de vendas em relação ao total das famílias (unidades). Fonte: Elaborado pelos autores (2013) com base na análise dos dados de campo. 
processo, e com pouca ou nenhuma alteração no desenho e especificações do produto.

A Figura 9 ilustra a quantidade de produtos por tipo de objetivo, os quais derivam da classificação

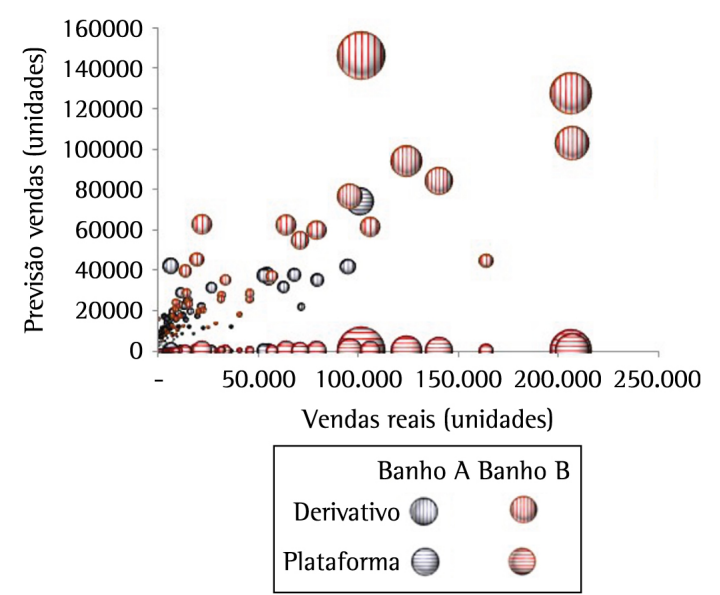

Figura 8. Quantidade de produtos por tipo de classe (2008-2010). Nota: Tamanho da bolha - proporção da previsão de vendas em relação ao total das famílias (unidades). Fonte: Elaborado pelos autores (2013) com base na análise dos dados de campo. de Griffin \& Page (1996). A família de produtos "Banho A" apresentou 26 produtos classificados como "novo para a empresa", 3 como "novo para o mundo", 118 como "acréscimo à linha existente" e 5 como "redução de custo". Já dos produtos da família "Banho B", um produto foi considerado como "novo para o mundo", 3 "como acréscimo à linha existente" e 45 como "redução de custo". A análise não identificou produtos classificados como "melhoria em produtos" ou "reposicionamento".

Quanto aos volumes projetados por meio da previsão de vendas, a família de produtos "Banho A" apresentou como média por produto uma previsão de vendas de 9.461 unidades por mês. Os produtos da família "Banho B" apresentaram uma média de previsão de vendas mensal de 33.672 unidades. Conforme já comentado anteriormente, esta grande diferença entre os volumes das famílias justifica-se devido aos produtos da família "Banho B" serem destinados à classe $\mathrm{C}$, tendo um preço reduzido e, consequentemente, maior expectativa de escala de vendas.

Em relação à margem de contribuição esperada pela empresa, para os produtos da família "Banho A" deseja-se uma margem de $40 \%$, e para os produtos da
Novo para a empresa

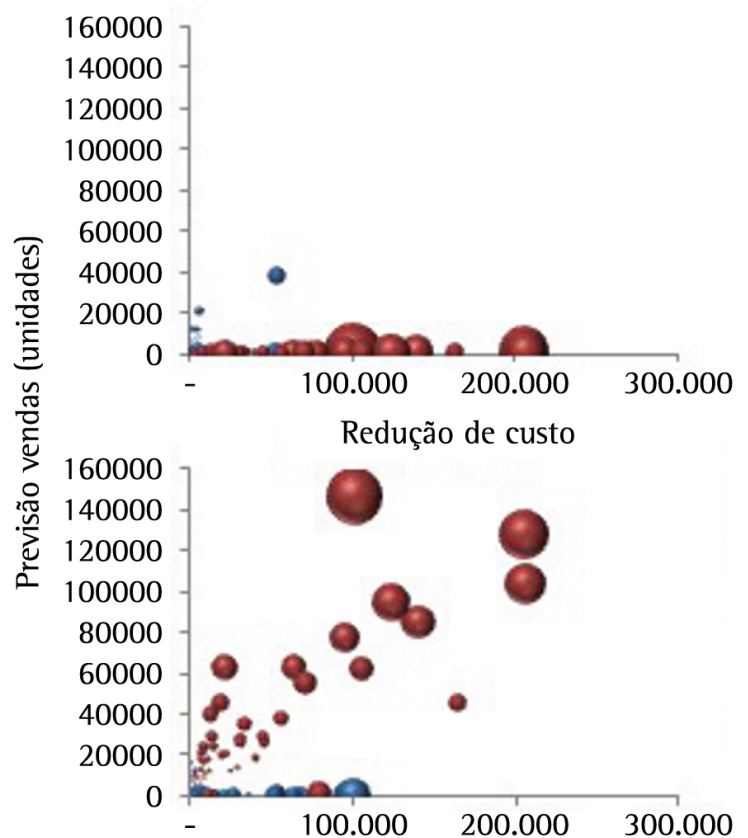

Novo para o mundo
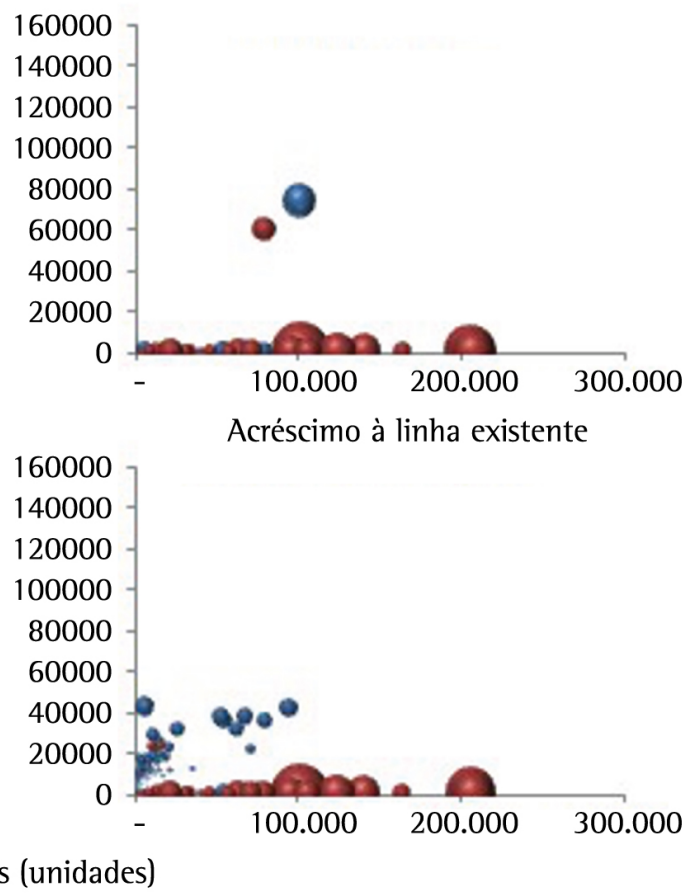

- Banho A • Banho B

Figura 9. Quantidade de produtos por tipo de objetivo (2008-2010). Nota: Tamanho da bolha - proporção da previsão de vendas em relação ao total das famílias (unidades). Fonte: Elaborado pelos autores (2013) com base na análise dos dados de campo. 
família "Banho B" a margem de contribuição desejada é de 35\%. Quanto à expectativa de tempo de vigência em mercado, nota-se por meio da Figura 10 que 137 produtos $(90,13 \%$ do total) da família "Banho A" possuem uma expectativa de permanecer de 6 a 12 meses em vigência no mercado, e 15 produtos (9,87\% do total) de 1 a 2 anos. Dos produtos da família de produtos "Banho B", todos os 49 apresentam uma expectativa de vigência em mercado de 6 a 12 meses. A maioria dos produtos, para ambas as famílias, possui uma expectativa de vigência em mercado de 6 a 12 meses. Isso ocorre devido ao fato de que, historicamente, após este período, muitos desses produtos têm uma significativa redução no seu volume de venda.

A Figura 11 mostra que, em relação à importância, dos produtos simulados na planilha de seleção e priorização de produtos, 15 produtos $(9,87 \%$ do total) da família "Banho A" classificam-se como "especialidade" e 137 (90,13\% do total) como "comum". Da família de produtos "Banho B", todos os 49 são classificados como sendo "comum", justificando-se
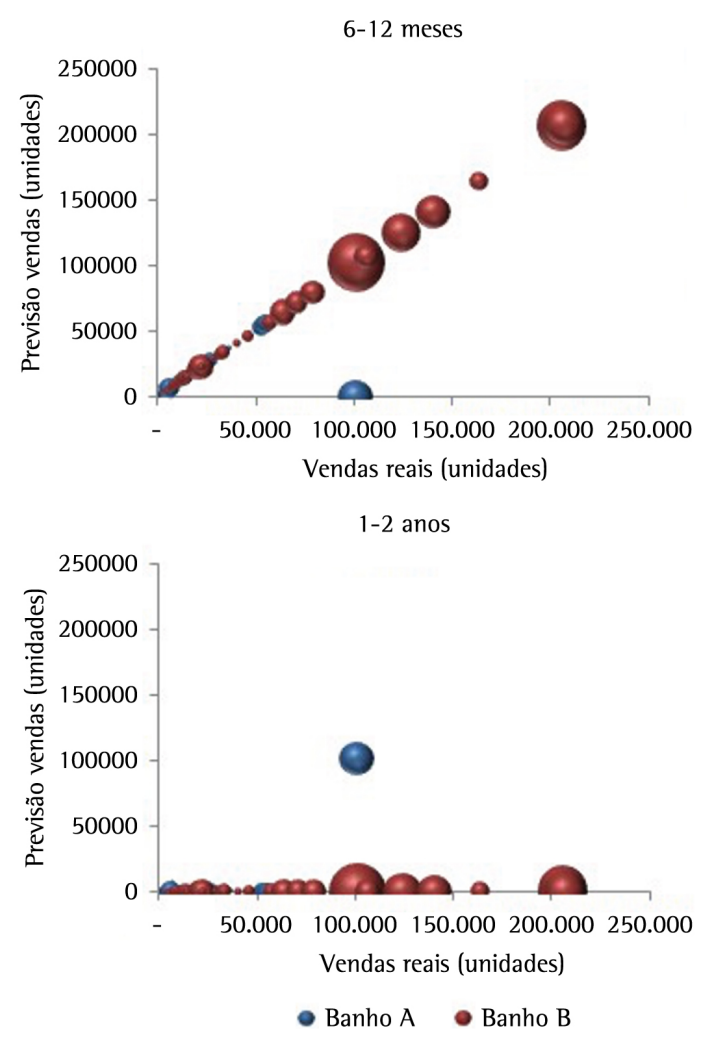

Figura 10. Quantidade de produtos por faixa de tempo de vigência em mercado (2008-2010). Nota: Tamanho da bolha - proporção da previsão de vendas em relação ao total das famílias (unidades). Fonte: Elaborado pelos autores (2013) com base na análise dos dados de campo. por serem produtos mais simplificados, no desenho e especificações do produto ou na sua fabricação.

A Tabela 3 mostra a classificação da quantidade de produtos priorizados na escala de 1 a 5 .

Seguindo os critérios estabelecidos pela planilha de seleção e priorização de produtos, e considerando que todos os 201 produtos estejam sendo avaliados no mesmo momento, pode-se observar na Tabela 3 que o maior percentual de produtos da família "Banho A" $(33,55 \%)$ classificou-se na prioridade 5 , e o maior percentual de produtos da família "Banho B" (32,65\%) classificou-se na prioridade 1. Conforme anteriormente discutido, cada produto teve sua priorização feita de forma individual, e, dependendo de avaliador para avaliador, a prioridade poderia alterar-se, devido ao julgamento a partir de critérios não totalmente objetivos/tangíveis, possibilitando interpretações e análises diferenciadas.

\subsection{Aplicação da proposta com dados históricos reais}

No intuito de se ter uma comparação da aplicação da proposta com dados históricos reais, fez-se uma análise dos critérios de margem de contribuição e volume de venda, comparando o previsto com o real. Como citado anteriormente, os produtos utilizados na priorização são produtos reais, e que já possuem um registro anterior de dados e informações que possibilitam esta comparação.

A Tabela 4 mostra a quantidade de produtos priorizados por prioridade atribuída, para as famílias de produtos "Banho A" e "Banho B", resultante da

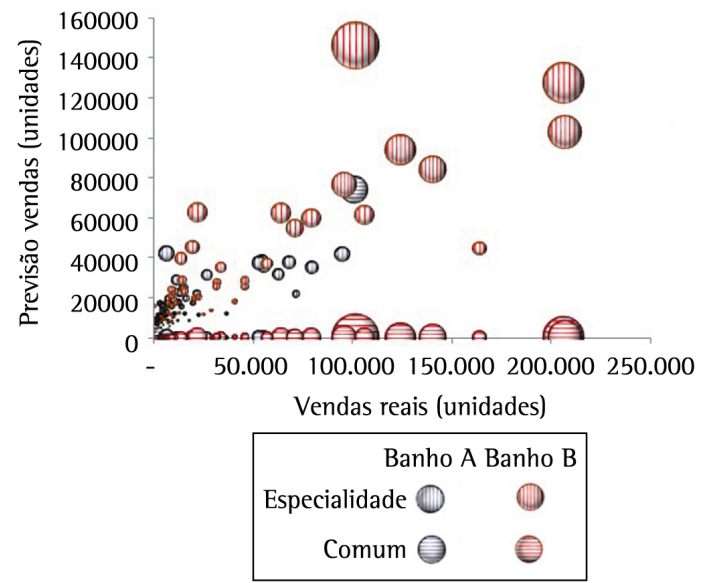

Figura 11. Quantidade de produtos por importância (2008-2010). Nota: Tamanho da bolha - proporção da previsão de vendas em relação ao total das famílias (unidades). Fonte: Elaborado pelos autores (2013) com base na análise dos dados de campo. 
Tabela 3. Priorização de produtos na proposta - "Banho A" e "Banho B".

\begin{tabular}{lcccccc}
\hline \multirow{2}{*}{ Família } & \multicolumn{5}{c}{ Prioridade } & Total \\
\cline { 2 - 6 } & $\mathbf{1}$ & 2 & 3 & 4 & 5 & \\
\hline Banho A & 39 & 23 & 24 & 15 & 51 & 152 \\
Banho B & 16 & 9 & 8 & 7 & 9 & 49 \\
Total & 55 & 32 & 32 & 22 & 60 & 201 \\
\hline
\end{tabular}

Fonte: Construído pelos autores (2013) com base na análise dos dados de campo.

Tabela 4. Priorização ocorrida a partir de dados reais - "Banho A" e "Banho B".

\begin{tabular}{lcccccc}
\hline & \multicolumn{5}{c}{ Prioridade } & Total \\
\cline { 2 - 6 } & $\mathbf{1}$ & 2 & 3 & 4 & 5 & \\
\hline Banho A & 16 & 15 & 21 & 15 & 85 & 152 \\
Banho B & 4 & 21 & 14 & 3 & 7 & 49 \\
Total & 20 & 36 & 35 & 18 & 92 & 201 \\
\hline
\end{tabular}

Fonte: Construído pelos autores (2013) com base na análise dos dados de campo.

comparação da aplicação da proposta com dados históricos reais. Todos os produtos tiveram uma nova priorização efetuada, com base nos critérios de margem de contribuição e volume de venda. Apenas as informações "realizadas" destes dois critérios foram utilizadas para a comparação, devido estas serem as informações que a empresa possuía em relação ao que realmente ocorreu referente aos critérios adotados.

Comparando-se a Tabela 3 com a Tabela 4, nota-se que existiram alterações em termos de priorização, conforme apresenta a Tabela 5. Em síntese, muitos produtos que eram mais prioritários deixaram de ser e foram classificados em outra prioridade, devido à comparação ter levado em consideração os critérios de margem de contribuição e volume de venda reais. Muitos destes produtos ficaram abaixo do esperado na priorização inicial.

Comparando o volume de venda previsto para a família de produtos "Banho A" no período de 2008-2010, nota-se que dos 152 produtos priorizados, apenas 36 deles, ou seja, 24\% tiveram um volume de venda mensal médio igual ou maior ao previsto. Comparando-se a soma mensal prevista de vendas para todos os 152 produtos, percebe-se que as vendas reais ficaram 10\% abaixo do previsto. Em relação à margem de contribuição (objetivo) da família de produtos "Banho A", nota-se que, dos 152 produtos priorizados, apenas 2 deles, ou seja, 1\% teve uma margem de contribuição igual ou maior à prevista.

Quando se efetua a mesma comparação para a família de produtos "Banho B", comparando o volume de venda previsto no período de 2008-2010, nota-se que dos 49 produtos priorizados, 23 deles, ou seja, $47 \%$ tiveram um volume de venda mensal médio igual ou maior que o previsto. Comparando-se a soma
Tabela 5. Diferença na quantidade de produtos priorizados na proposta e dados reais - "Banho A" e "Banho B".

\begin{tabular}{lccccc}
\hline \multirow{2}{*}{ Família } & \multicolumn{5}{c}{ Prioridade } \\
\cline { 2 - 6 } & 1 & 2 & 3 & 4 & 5 \\
\hline Banho A & -23 & -8 & -3 & 0 & 34 \\
Banho B & -12 & 12 & 6 & -4 & -2 \\
Total & -35 & 4 & 3 & -4 & 32 \\
\hline
\end{tabular}

Fonte: Elaborado pelos autores (2013) com base na análise dos dados de campo.

mensal prevista de vendas para todos os 49 produtos, percebe-se que as vendas reais ficaram $21 \%$ acima do previsto. Em relação à margem de contribuição (objetivo) da família de produtos "Banho B", nota-se que dos 49 produtos priorizados, apenas 2 deles, ou seja, 4\% tiveram uma margem de contribuição igual ou maior à prevista.

As razões para o fato de as margens de contribuição estarem inferiores às previstas são associadas aos seguintes fatores:

- Mercadológicos, como por exemplo, políticas comerciais agressivas (descontos) fazem as margens de contribuição ficarem abaixo do esperado;

- Variação de custos incorridos durante os processos de produção como, por exemplo, aquisição de matéria-prima com preços superiores aos orçados, aumentando assim o custo dos produtos;

- Constatação feita na survey da PDMA (ver Loos \& Miguel, 2012), onde a empresa deixa claro que "não interrompe produtos após iniciados, mesmo estando abaixo da performance";

- Superdimensionamento pela empresa em relação às expectativas quanto às margens, visto que, para todos os produtos dentro de uma família, as margens esperadas são as mesmas.

Quanto aos volumes de faturamento terem ficado abaixo do esperado para muitos produtos de ambas as famílias (76\% para "Banho A" e 53\% para "Banho B"), nota-se como principal causa o fato de a empresa efetuar suas previsões de vendas baseando-se em histórico de faturamento, ou seja, pode estar constantemente dimensionando as vendas de forma elevada devido ao faturamento ocorrido não retratar de forma transparente se o produto está ou não tendo giro de vendas nos canais de venda. Este tipo de fato geralmente se resolve com a implantação de um sistema VMl (Vendor Managed Inventory), no qual o fornecedor passa a ser responsável pela administração dos níveis de estoques dos clientes, trazendo a real visualização de como está o giro dos produtos. É importante frisar que esta causa de superdimensionar as vendas faz com que a empresa incorra, muitas vezes, na causa da política comercial, 
onde, após ter planejado e produzido um excessivo volume de determinado produto, e este não ter as vendas esperadas, para conseguir fazer este item "girar", frente aos itens recém-lançados, a empresa precisa praticar descontos elevados para conseguir vender, diminuindo as margens de contribuição esperadas.

Apesar de a comparação da aplicação da proposta com os dados históricos reais ter apresentado uma significativa alteração da priorização efetuada inicialmente, considera-se que a proposta não pode ser totalmente invalidada, visto que os motivos da alteração da priorização foram identificados, e o propósito da comparação era realmente testar a proposta e avaliar o comportamento da mesma.

\section{Conclusões}

Primeiramente cabe destacar que, ao utilizar a classificação dos projetos da literatura de acordo com o "grau de novidade para o mercado" e "grau de novidade para a empresa", possibilita-se ter a visão da interligação que os projetos possuem com as estratégias empresarias, fator este considerado como relevante na literatura. Esta interligação serve como norteadora para o desenvolvimento de novos produtos que estejam de acordo com as estratégias da empresa.

A definição de critérios estratégicos, para serem levados em consideração ao selecionar e priorizar os projetos mais adequados para o desenvolvimento dos produtos, é uma das etapas mais importantes na gestão de portfólio, visto que a seleção equivocada de critérios pode acarretar na introdução de projetos totalmente desconexos com a necessidade da organização. A definição desses critérios, caso seja embasada e definida por comitês específicos que conheçam o portfólio de produtos e as necessidades da organização, tende a ser mais facilmente assertiva e coerente.

Por meio da proposta de gestão de portfólio efetuada, possibilitou-se que a seleção e priorização de produtos a serem desenvolvidos pela empresa ocorressem de forma estruturada e criteriosa, fazendo com que os produtos corretos, ou seja, os que estejam mais fortemente alinhados com a estratégia da empresa fossem desenvolvidos. Apesar de alterações de prioridades terem ocorrido na etapa de comparação da aplicação da proposta, a mesma apresentou-se como uma forma viável de se ter o início da gestão de portfólio mais sistematizada, trazendo maior segurança para desenvolvimento de novos produtos, por meio de um sequenciamento mais assertivo e embasado. 0 presente trabalho contribui com um resultado empírico para desenvolver uma proposta para a seleção e priorização de produtos. Analiticamente, a proposta pode efetivamente atender as necessidades de uma organização como a investigada, embora com limitações. Ao considerar essas limitações, este estudo oferece estrutura para uma empresa tomar decisões no que diz respeito à gestão de portfólio de produtos. Esta proposta inicial tem, portanto, o potencial de contribuir para a vantagem competitiva de uma empresa. Este modelo de seleção e priorização de produtos proposto carece ainda ser testado e aplicado em empresas similares ou ainda de outros setores industriais, visando efetuar outros ajustes necessários, buscando maior eficácia em diferentes cenários organizacionais.

\section{Referências}

Archer, N. P., \& Ghasemzadeh, F. (1999). An integrated framework for project portfolio selection. International Journal of Project Management, 17(4), 207-216. http:// dx.doi.org/10.1016/S0263-7863(98)00032-5.

Associação Brasileira da Indústria Têxtil e de Confecção ABIT. (2011). Apresenta informações sobre o perfil do setor têxtil. São Paulo: ABIT. Recuperado em 7 de Julho de 2011, de http://www.abit.org.br/site/navegacao. asp?id_menu=1\&id_sub=4\&idioma=PT.

Castro, H. G., \& Carvalho, M. M. (2010). Gerenciamento do portfólio de projetos: um estudo exploratório. Gestão \& Produção, 17(2), 283-296. http://dx.doi.org/10.1590/ S0104-530X2010000200006.

Chen, H. H., Kang, H. Y., Xing, X., Lee, A. H. I., \& Tong, Y. (2008). Developing new products with knowledge management methods and process development management in a network. Computers in Industry, 59(2-3), 242-253. http:// dx.doi.org/10.1016/j.compind.2007.06.020.

Cheng, L. C. (2000). Caracterização da gestão de desenvolvimento do produto: delineando o seu contorno e dimensões básicas. In Anais do ll Congresso Brasileiro de Gestão de Desenvolvimento de Produto, São Carlos, SP.

Coldrick, S., Longhurst, P., lvey, P., \& Hannis, J. (2005). An R\&D options selection model for investment decisions. Technovation, 25(3), 185-193. http://dx.doi.org/10.1016/ S0166-4972(03)00099-3.

Cooper, R. G., Edgett, S. J., \& Kleinschmidt, E. J. (1997a). Portfolio management in new product development: lessons from the leaders - 1. Research-Technology Management, 4O(5), 16-28.

Cooper, R. G., Edgett, S. J., \& Kleinschmidt, E. J. (1997b). Portfolio management in new product development: lessons from the leaders - 11. Research Technology Management, 4O(6), 16-27.

Cooper, R. G., Edgett, S. J., \& Kleinschmidt, E. J. (1998). Portfolio management for new products. Reading: Addison-Wesley.

Cooper, R. G., Edgett, S. J., \& Kleinschmidt, E. J. (2000). New problems, new solutions: making portfolio management more effective. Research Technology Management, 43(2), 18-33.

Cooper, R. G., Edgett, S. J., \& Kleinschmidt, E. J. (2001a). Portfolio management for new product development: results of an industry practices study. $R \& D$ Management, 31(4), 361-380. http://dx.doi.org/10.1111/1467-9310.00225. 
Cooper, R. G., Edgett, S. J., \& Kleinschmidt, E. J. (2001b). Portfolio management for new products (2. ed.). New York: Basic Books.

Cooper, R. G., Edgett, S. J., \& Kleinschmidt, E. J. (2004). Benchmarking best NPD practices - 1. Research Technology Management, 47(1), 31-43.

Griffin, A. (1997). PDMA research on new product development practices: updating trends and benchmarking best practices. Journal of Product Innovation Management, 14(6), 429458. http://dx.doi.org/10.1016/S0737-6782(97)00061-1.

Griffin, A., \& Page, A. (1996). PDMA success measurement project: recommended measures for product development success and failure. Journal of Product Innovation Management, 13(6), 478-496. http://dx.doi.org/10.1016/ S0737-6782(96)00052-5.

Gunasekaran, A. (1998). An integrated product developmentquality management system for manufacturing. The TQM Magazine, 10(2), 115-123. http://dx.doi. org/10.1108/09544789810211425.

Hamilton, A. (2002). Considering value during early project development: a product case study. International Journal of Project Management, 20(2), 131-136. http://dx.doi. org/10.1016/S0263-7863(00)00052-1.

Kendall, G. 1., \& Rollins, S. C. (2003). Advanced project portfolio management and PMO multiplying ROI at warp speed. Boca Raton: J. Roos Publishing.

Lockett, M., De Reyck, B., \& Sloper, A. (2008). Managing project portfolios. Business Strategy Review, 19(2), 77-83. http:// dx.doi.org/10.1111/j.1467-8616.2008.00540.x.

Loos, M. J., \& Miguel, P. A. C. (2011). Análise da classificação de projetos de novos produtos e faturamento no desenvolvimento de produtos em uma empresa têxtil. RACE: Revista de Administração, Contabilidade e Economia, 10(2), 185-214.

Loos, M. J., \& Miguel, P. A. C. (2012). Product portfolio management practices based on the PDMA survey: a diagnostic in a textile company. Espacios, 33(6), 6-12.

Mahdi, l. M., \& Alreshaid, K. (2005). Decision support system for selecting the proper project delivery method using analytical hierarchy process (AHP). International Journal of Project Management, 23(7), 564-572. http://dx.doi. org/10.1016/j.jproman.2005.05.007.

McFarlan, F. W. (1981). Portfolio approach to information. Harvard Business Review, 59(5), 142-150.

McNally, R., Durmusoglu, S. S., Calantone, R. J., \& Harmancioglu, N. (2009). Exploring new product portfolio management decisions: the role of managers' dispositional traits. Industrial Marketing Management, 38(1), 127-143. http://dx.doi. org/10.1016/j.indmarman.2007.09.006.

Meyer, M. H. (1997). Revitalize your product lines through continuos platform renewal. Research Technology Management, 40(2), 17-28.

Miguel, P. A. C. (2008). Implementação da gestão de portfólio de novos produtos: um estudo de caso. Production, 18(2), 388-404.
Mikkola, J. H. (2001). Portfolio management of R\&D projects: implications for innovation management. Technovation, $21(7)$, 423-435. http://dx.doi.org/10.1016/S01664972(00)00062-6.

Moore, S. (2010). Strategic project portfolio management: enabling a productive organization. Hoboken: Wiley.

Moraes, R. 0., \& Laurindo, F. J. B. (2003). Um estudo de caso da gestão de portfólio de projetos de tecnologia de informação. Gestão \& Produção, 10(3), 311-328. http:// dx.doi.org/10.1590/S0104-530X2003000300007.

Oliveira, G. N., \& Cheng, L. C. (2007). Construindo um sistema de desenvolvimento de produto em empresa têxtil por intermédio de gestão de portfólio. In Anais do $6^{\circ}$ Congresso Brasileiro de Desenvolvimento do Produto, Belo Horizonte, MG.

Padovani, M., Carvalho, M. M., \& Muscat, A. R. (2010). Seleção e alocação de recursos em portfólio de projetos: estudo de caso no setor químico. Gestão \& Produção, 17(1), 157-180. http://dx.doi.org/10.1590/S0104-530X2010000100013.

Padovani, M., Muscat, A. R., Camanho, R., \& Carvalho, M. M. (2008). Looking for the right criteria to define projects portfolio: multiple case study analysis. Product: Management \& Development, 6(2), 127-134.

Poolton, J., \& Barclay, 1. (1998). New product development from past research to future applications. Industrial Marketing Management, 27(3), 197-212. http://dx.doi.org/10.1016/ S0019-8501(97)00047-3.

Product Development and Management Association. (2010). 2nd annual planview product portfolio management benchmark study. Austin: CHE Manager International.

Project Management Institute. (2008). The standard for portfolio management (2. ed.). Newton: ANSI.

Rabechini Junior, R., Maximiano, A. C. A., \& Martins, V. A. (2005). A adoção de gerenciamento de portfólio como uma alternativa gerencial: o caso de uma empresa prestadora de serviço de interconexão eletrônica. Production, 15(3), 416-433.

Roussel, P. A., Saad, K. N., \& Erickson, T. J. (1991). Third generation R\&D: managing the link to corporate strategy. Boston: Harvard Business School Press/ Arthur D. Little.

Rozenfeld, H., Forcellini, F. A., Amaral, D. C., Toledo, J. C., Silva, S. L., Alliprandini, D. H., \& Scalice, R. K. (2006). Gestão de desenvolvimento de produtos: uma referência para a melhoria do processo. São Paulo: Saraiva.

Turnbull, P. W. (1989). A review of portfolio planning models for industrial marketing and purchasing management. European Journal of Marketing, 24(3), 7-22. http://dx.doi. org/10.1108/03090569010000629.

Wei, C. C., \& Chang, H. W. (2011). A new approach for selecting portfolio of new product development projects. Expert Systems with Applications, 38(1), 429-434. http://dx.doi. org/10.1016/j.eswa.2010.06.081.

Wit, A. (1988). Measurement of project success. International Journal of Project Management, 6(3), 164-170. http:// dx.doi.org/10.1016/0263-7863(88)90043-9. 


\title{
Proposal for selecting and prioritizing a portfolio of new products in a textile company
}

\begin{abstract}
Product portfolio management is responsible for maintaining the competitive position of an organization, properly allocating resources for new product development, and assuring greater objectivity and effectiveness in the selection of new products. Companies in various industries have structured their portfolio management processes with these goals in mind when developing new products. In this context, this paper develops a proposal for selecting and prioritizing projects for new products for a manufacturer of textile products. After an initial assessment that identified opportunities for improvement in product portfolio management, the proposal was constructed based on criteria such as strategic importance, contribution margins, and sales volume forecasts. The proposal was then compared with historical data. It was found that significant changes were necessary in the prioritization of products to be developed due to factors such as the over-dimensioning of contribution margins and sales volumes. The proposal allows for a better structured process of the selection and prioritization of products to be developed while achieving a more rigorous selection process.
\end{abstract} Keywords

Portfolio management. Product development. New product selection. Textile company. 
Loos, M. J. et al.

Proposta de seleção e priorização ... produtos em uma empresa têxtil. Production, 26(4), 801-817, out./dez. 2016

Anexo 1. Síntese dos resultados correspondentes às Etapas 11 e 111.

Objetivo: Realizar um diagnóstico das práticas de gestão de portfólio de produtos da empresa pesquisada

Contexto/Resultados: Esse trabalho foi feito com base no preenchimento de um questionário da Associação Americana de Desenvolvimento de Produto (PDMA - Product Development Management Association). 0 objetivo do questionário foi identificar:

- Problemas primários e os riscos na gestão de uma carteira de produtos;

- Precisão de investimento, projeções e previsões em termos de custo, tempo e receita esperada;

- Desafios associados à gestão de recursos;

- Avaliação e capacidade para projetos de baixo desempenho final;

- 0 uso de soluções de gestão de portfólio de produtos e instrumentos alternativos.

Com base nas principais constatações desse diagnóstico, quando comparadas as questões entre as empresas do levantamento feito pelo PDMA e a empresa pesquisada, pode-se afirmar que, em âmbito geral, a empresa pesquisada apresenta muitas semelhanças nos seus resultados em comparação dos respondentes do PDMA, sendo as principais semelhanças observadas quanto as empresas: (i) possuem muitos projetos para os recursos disponíveis; (ii) suas decisões acontecem tardiamente ou ineficientemente; (iii) o gerenciamento das mudanças de prioridades e perda de janelas sazonais apresentam riscos; (iv) integram a voz do cliente no PDP; (v) consideram o alinhamento estratégico extremamente importante e possuem como desafio a incapacidade de ver a demanda de recursos previstos. Observa-se, no entanto, algumas oportunidades de melhoria em relação ao processo de planejamento e gerenciamento do portfólio de produtos existentes na empresa pesquisada. Assim, constatou-se que a implantação de uma proposta de seleção e priorização de produtos auxiliaria a empresa a solucionar alguma dessas lacunas, visando uma melhoria, visto que uma proposta de seleção e priorização descrita tornaria a gestão de portfólio da empresa mais bem organizada.

Objetivo: Realizar um diagnóstico das famílias de produtos da empresa, no sentido de ter um melhor direcionamento na aplicação da proposta.

Contexto/Resultados: A concentração do percentual de faturamento médio por família (2008-2010) ficou em três famílias de produtos: "Banho A" (29,64\%), "Banho B" (29,58\%) e "Cama" (19,73\%), ficando os 21,05\% restantes distribuídos entre as demais famílias. Esse foi o fator decisivo para que a proposta de seleção e priorização do portfólio tivesse como escolha, para a aplicação, as famílias de "toalhas felpudas" (A e B). Em relação ao faturamento dos produtos por tempo de vigência no mercado, nota-se que a maior parcela do faturamento de todas as famílias ocorre em produtos com vigência de até 6 meses (31,64\%) e até 12 meses (30,91\%), quando os mesmos são encarados como novidades no mercado e ainda não perderam espaço, bem como não foram afetados por outros lançamentos da própria empresa, os quais podem gerar "canibalismo" entre os produtos. Em suma, os resultados desse trabalho foram norteadores para que a proposta de seleção e priorização do portfólio de novos produtos na empresa têxtil fosse desenvolvida. Essa proposta possibilitou um maior aprofundamento na identificação de como as famílias de produtos da empresa se portavam, com base nas famílias "Banho A" e "Banho B", como mencionado anteriormente.

Fonte: Construído pelos autores (2013) com base na análise dos dados de campo. 